\title{
Three-Dimensional Organization of the Collagen Fibrillar Framework in the Rat Adrenal Gland*
}

\author{
Akio KikUta, Osamu Ohtani and Takuro Murakami \\ Department of Anatomy, Okayama University Medical School, Okayama, Japan \\ Received November 30, 1989; revised manuscript received January 4, 1991
}

Summary. The three-dimensional organization of the collagen fibrillar framework in the rat adrenal gland was studied using an alkali-water maceration method and scanning electron microscopy. The structure thus obtained was a continuum of collagen fibril plexuses extending through the adrenal capsule, cortex and medulla. The capsule consisted of finely meshed collagen fibril sheaths and layered, coarsely meshed plexuses of bundles of collagen fibrils. In the cortex, the channels of cortical capillaries were surrounded by thin sheaths of collagen fibrils. Many slender bundles of collagen fibrils extended from these sheaths into intercellular spaces and interconnected adjacent pericapillary sheaths. The collagen fibril sheath tubes precisely reflected the cortical blood vascular architecture; thus the three cortical zones-zona glomerulosa, zona fasciculata and zona reticularis - were also clearly remarked. In the medulla, collagen fibrils were interwoven into more tightly meshed sheaths around the peripheral radicles and venous tributaries of the central veins. Basket-like collagen fibril sheaths divided the spaces among these tree-like perivascular collagen fibril sheath tubes into round compartments which, in intact tissues, contained chromaffin cell nodules and nervous elements. Small tube-like spaces for housing the medullary capillaries were located in the interstices of contiguous collagen fibril baskets. Besides supporting the organization of the gland, the collagen fibrillar framework in the adrenal gland is believed to play important roles in providing three-dimensionally elaborated extravascular spaces for the diffusion of metabolites and physiological messengers, including hormones.

The connective tissue fibers, collagen and reticular fibers, of the reticulum of the adrenal gland have been intensively investigated by light microscopy using various methods, such as cell maceration (MALL, 1896; FLINT, 1900) and silver impregnation techniques
(LeVER, 1952; PAUly, 1957). These have revealed that the configuration of the adrenal reticulum reflects the arrangement of the adrenal parenchymal cells and blood vessels, besides representing the tissue skeletal framework supporting the parenchymal cells (PAULY, 1957). Recently, the reticulum has been intensely studied in various organs for its important role as extracellular matrix, and it has also been established that the most plentiful and main component of the reticulum is collagen.

On the other hand, the connective tissue spaces, where collagen fibrils are located to form reticulum, are vascularized; these spaces also serve as main paths of extravascular fluid and substances (KIHARA, 1950; Abraham et al., 1976; CASEley-Smith, 1977; MeYer and SilberberG, 1977). These spaces may also function as fields for the paracrine transport of various physiological messengers, such as neuropeptides and amines released from nerve terminals and endocrine cells (FuJITA, 1983; FuJITA et al., 1988). In the adrenal gland, many peptidic messenger substances other than steroids and amines have recently been found to be produced and released. Since the release amount of these substances is small, it is inferred that the extension of their effective range is restricted locally and highly dependent on the spatial configuration of diffusion spaces, intercellular and connective tissue spaces. Thus, it is also essential to elucidate the three-dimensional extension of the spaces where these physiological messengers are released and diffused.

Visualization of a detailed three-dimensional configuration of the connective tissue spaces or reticulum, however, has been remained a challenge because of the limited facilities of light microscopy and the absence of effective preparation techniques in electron

*The present study was supported by a grant (No. 63570009) from the Ministry of Education, Science and Culture, Japan. 
microscopy. In the present study, we prepared specimens of the collagen fibrillar framework in the rat adrenal gland by using a maceration method recently developed (OHTANI, 1987, 1988; OHTANI et al., 1988), examining them by scanning electron microscopy.

\section{MATERIALS AND METHODS}

Adult Wistar strain rats (250-350 g) were used. The animals, anesthetized with ethyl ether, were perfused via the thoracic aorta with a Ringer solution followed by $2.5 \%$ glutaraldehyde in $0.1 \mathrm{M}$ phosphate buffer $(\mathrm{pH}$ 7.4). Thereafter, the posterior abdominal wall was flooded with the fixative. Five minutes later the adrenal glands were removed and cut transversely or longitudinally into two halves. These tissue blocks were immersed in the fixative for 2 to 3 days.

Sections, $60-100 \mu \mathrm{m}$ thick, were cut in a vibratome (model G, Oxford Laboratories, U.S.A), until a section containing both adrenal medullary arteries and the central vein was obtained. This section was treated with a $2.0 \%$ potassium dichromic solution and light-microphotographed for later references. The remaining tissue blocks were processed using a slightly modified cell-digestion method by OHTANI (1987). The specimens were immersed in a $2 \mathrm{~N} \mathrm{NaOH}$ aqueous solution for 2 or 3 days at 20 to $25^{\circ} \mathrm{C}$. The specimens were further macerated and washed in distilled water for 5-7 days until the specimen became pale and transparent. The specimens were immersed for $3 \mathrm{~h}$ in a $1.0 \%$ aqueous solution of tannic acid, rinsed overnight in distilled water, and treated for $3 \mathrm{~h}$ with a $1.0 \%$ aqueous osmic acid (the conductive staining by MURAKAMI, 1974).

The specimens were dehydrated by ascending concentrations of ethanol and critical point-dried in a critical point dryer (HCP-2, Hitachi) using liquid $\mathrm{CO}_{2}$. The dried specimens were mounted on brass stubs with double-sided sticky tape and coated with goldpalladium in a Polaron SEM coating system (Polaron Equipment, Watford, England). The specimens were observed with a scanning electron microscope (JSM U-3, JEOL or HHS-2R, Hitachi) at an accelerating voltage of $15 \mathrm{kV}$. Usually, stereo paired microphotographs were prepared, tilting one of the pairs 7 degrees in order to facilitate three-dimensional observation.

Several glutaraldehyde fixed tissue blocks were processed for transmission electron microscopy and were postfixed with $1.0 \%$ osmic acid in $0.1 \mathrm{M}$ phosphate buffer ( $\mathrm{pH}$ 7.4). Some of the specimens were treated with $0.5 \%$ tannic acid in the same buffer before postfixation. The tissues were dehydrated by ascending concentrations of ethanol and propylene oxide and embedded in epoxy resin (Epon 812). Thin sections, $60-80 \mathrm{~nm}$ thick, and thick sections, $150-200$ $\mathrm{nm}$ thick, were cut and stained with uranyl and lead citrate. These sections were observed with a Hitachi H-700 electron microscope.

\section{RESULTS}

Alkali-water maceration at room temperature removed essentially all of the tissue elements, leaving only a collagen fibril network (Figs. 1-8). The three-dimensional configuration of the collagen fibril network was entirely preserved, allowing visualization of the characteristic meshwork patterns of the capsule, cortex and medulla (Figs. 1-8). Figures 1a-d are progressively magnified scanning electron micrographs of the rat adrenal collagen fibrillar framework. High magnifications (Fig. 1c, d) evidence that the remaining structure is composed of numerous slender fibrils of uniform diameters $60-80 \mathrm{~nm}$.

The macerated capsule of rat adrenal glands consisted of several layers composed of interlaced collagen fibrils. The removal of the individual layers of the capsular collagen fibril network with forceps revealed the configuration of each layer of the fibril network (Fig. 2). The surface layer of the capsule was a finely meshed fibril sheath, randomly woven with slender bundles, $0.5-2 \mu \mathrm{m}$ thick, of collagen fibrils. In this layer many round and oval meshes of $1-2 \mu \mathrm{m}$ diameters were observed (Fig. 2a). Beneath this layer extended a coarser plexus of thicker bundles of collagen fibrils of 1-4 $\mu \mathrm{m}$ diameters. The thickest

\footnotetext{
Fig. 1. SEM views of the collagen fibrillar network of the rat adrenal gland, magnified stepwise through a-d. a. A low magnification, cross sectional view. Collagen frameworks of the cortex $(C)$ and medulla $(M)$ show characteristic meshwork patterns. $C V$ adrenal central vein. $\times 100$. b. A magnified view of a portion of Fig. 1a. The medullary region $(M)$ is divided by collagen sheaths into basket and tube-like, small compartments, where chromaffin cell clusters and blood vessels are located in intact tissues. The space for the adrenal central vein $(C V)$ and its large venous radicles $(L V)$. $C$ cortex. $\times 300$. c. A SEM view of the intercalating collagen fibrillar septa between the adjacent two chromaffin cell clusters. Each compartment housing chromaffin cells is not completely isolated but continuous through a few fenestrae $(F)$ in the collagen fibrillar wall. $\times 3,000$. d. A highly magnified view of the clollagen fibrillar sheath. Individual collagen filaments can be distinguished. $\times 10,000$
} 


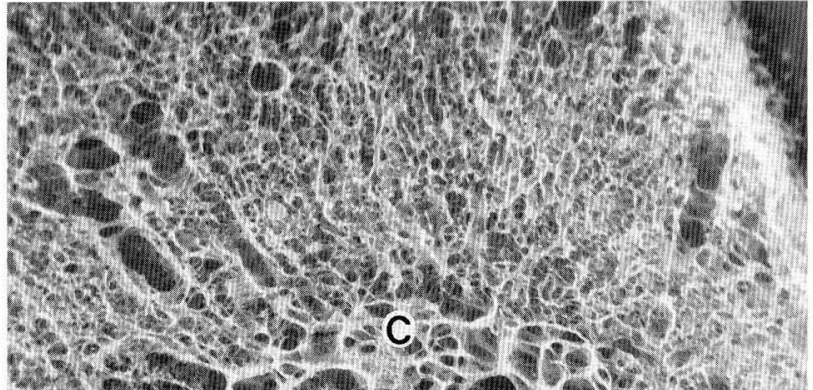

Con

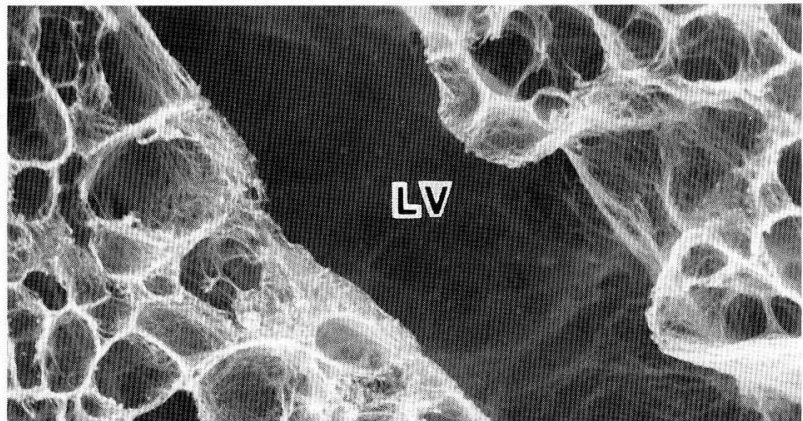

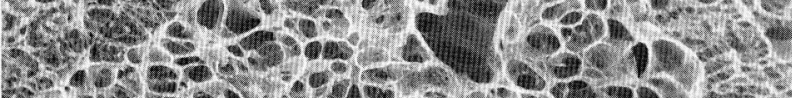

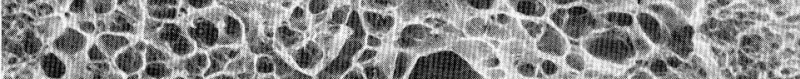

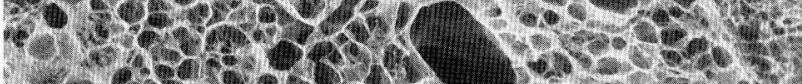

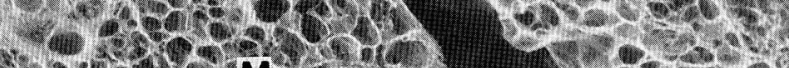

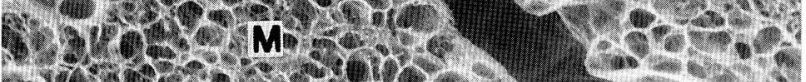
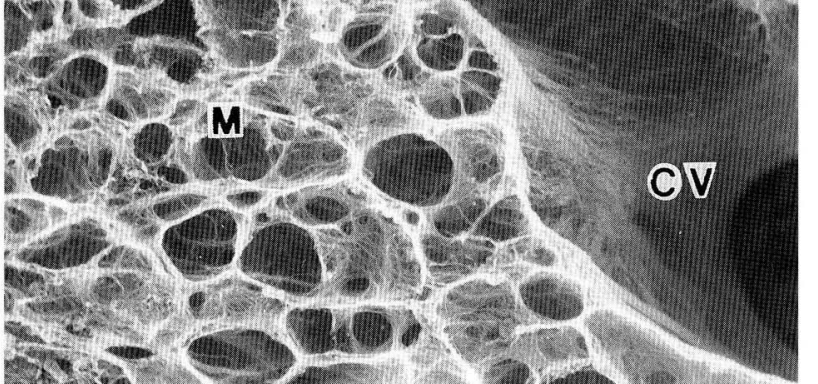

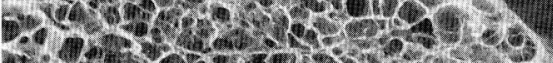

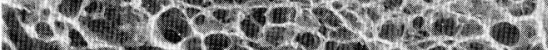
Q

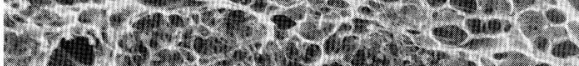

\section{CV}

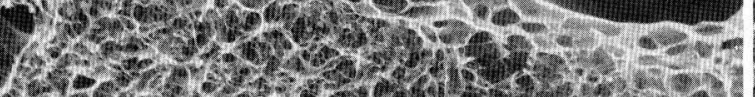

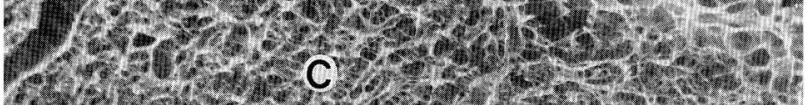

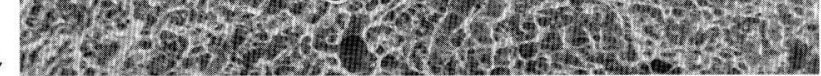

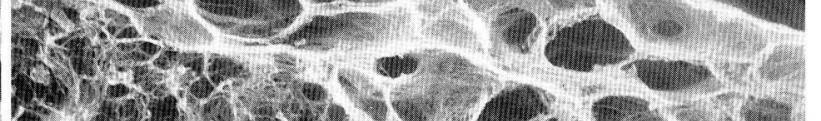
3.

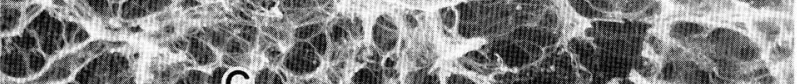

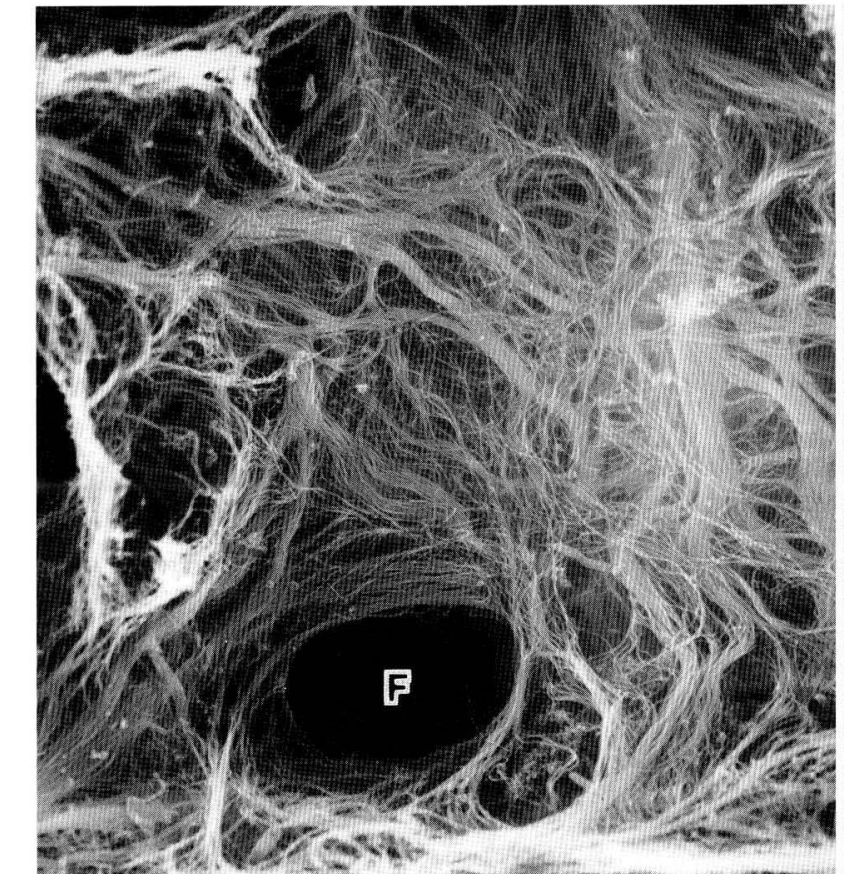
4 - C 9.7. a 1.

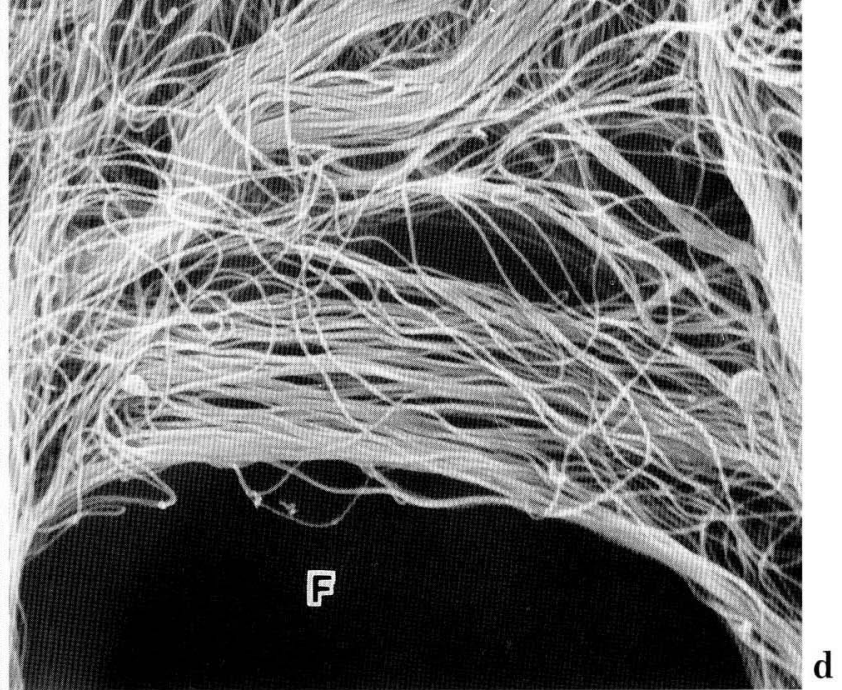

Fig. 1. Legend on the opposite page. 


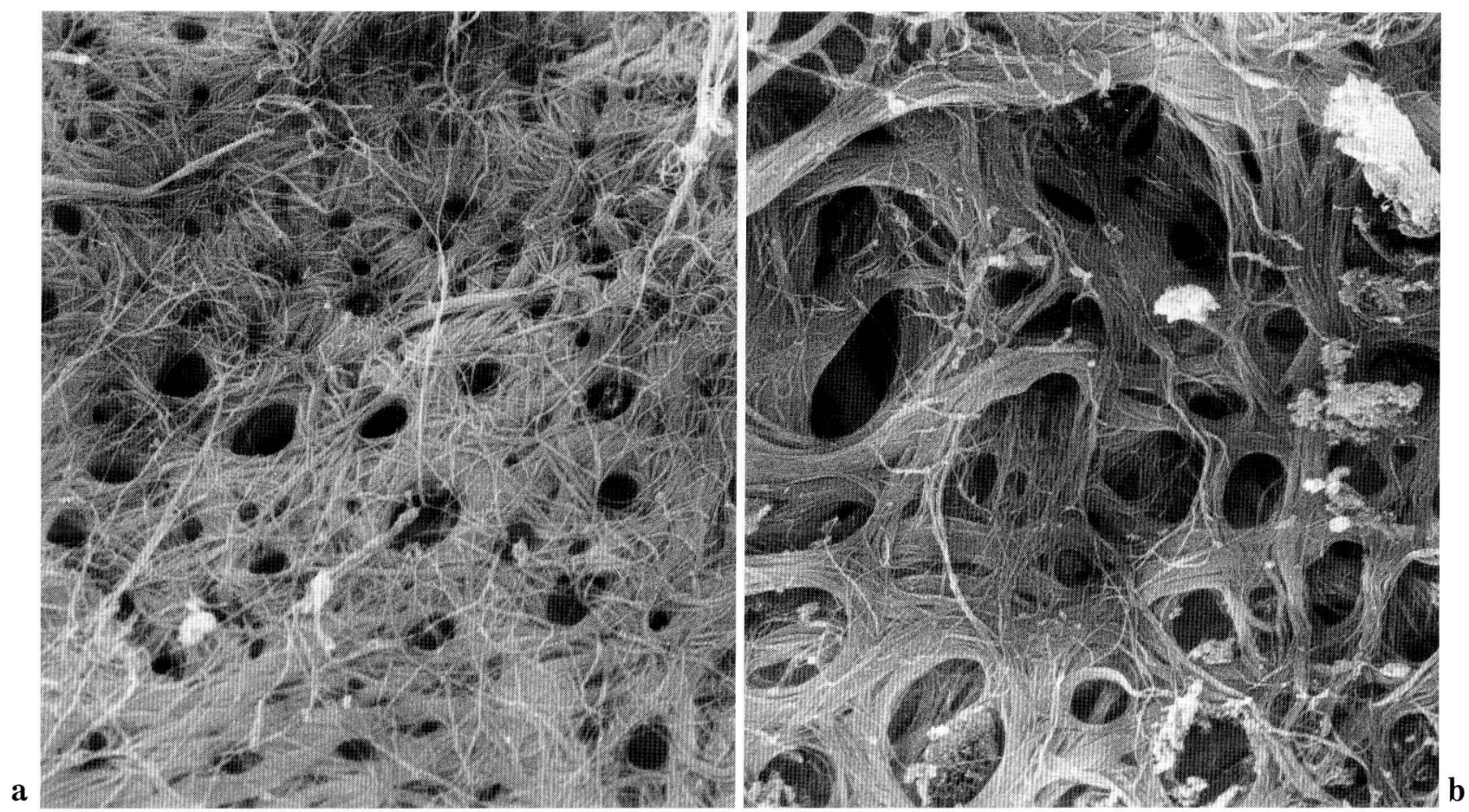

Fig. 2. SEM views of the collagen fibrillar network of the capsule of the rat adrenal gland. a. Outermost fine meshed collagen network. $\times 3,000$. b. A coarse collagen plexus composed of thick bundles. $\times 3,000$

bundles were composed of several hundreds of collagen fibrils. These bundles repeatedly divided and fused to form a three-dimensional spongy plexus having large round mesh spaces of $20-30 \mu \mathrm{m}$ in caliber. Many slender bundles thinner than $1 \mu \mathrm{m}$ or single collagen fibrils arose from these main bundles to form secondary plexuses of finer meshes (Fig. 2). Collagen fibrils tended to spin out from thick bundles and ran in waves to form finer fibril sheaths extending within the layer.

At the junction of the capsule and the zona glomerulosa of the adrenal cortex, many fine bundles of collagen fibrils spun out centripetally from the capsular plexuses. A few thick bundles ran out from the capsule straight through the zona glomerulosa.

The collagen fibrillar framework of the zona glomerulosa was continuous with that of the capsule (Fig. 3). Round basket-like frameworks with open spaces 15-20 $\mu \mathrm{m}$ wide were observed. These individual spaces, corresponding to the spaces, housed clusters of zona glomerulosa cells in intact glands. In the interstices of these basket-like collagen sheaths remained tortuous, tube-like spaces for housing the capillaries of the zona glomerulosa.

In the zona fasciculata principally two types of collagen networks were observed. In the subendo- thelial spaces, collagen fibrils formed pericapillary sheaths with fine meshes (Figs. 4, 5). The other type was intercellular coarse networks made of bundles of collagen fibrils. Slightly thicker collagen bundles not exceeding $1 \mu \mathrm{m}$ in thickness were observed in the intercellular spaces which extended parallel to the capillaries running centripetally (Fig. 4). These bundles gave rise from the perivascular collagen sheaths and connected the adjacent two perivascular capillary sheaths, thus giving the appearance of ladder rungs (Figs. 4, 6). Few collagen fibrils traversed within the intercellular spaces which extended between the consecutive two parenchymal cells in a cell cord of the zona fasciculata. Thus, in the collagen fibrillar framework of the zona fasciculata, two kinds of tube-like hollow rooms were formed (Figs. 4-6), one being complete tubes for blood vessels, whereas the other was incomplete, short spaces housing cortical cell strands of the zona fasciculata. In the bifurcating portions of the pericapillary collagen sheath tubes, occasionally fine-meshed collagen fibril plexus were formed.

In the zona reticularis, the collagen framework presented a different appearance from that of the zona fasciculata (Fig. 6). In this zone, pericapillary collagen tubes took a tortuous arrangement (Fig. 6). 

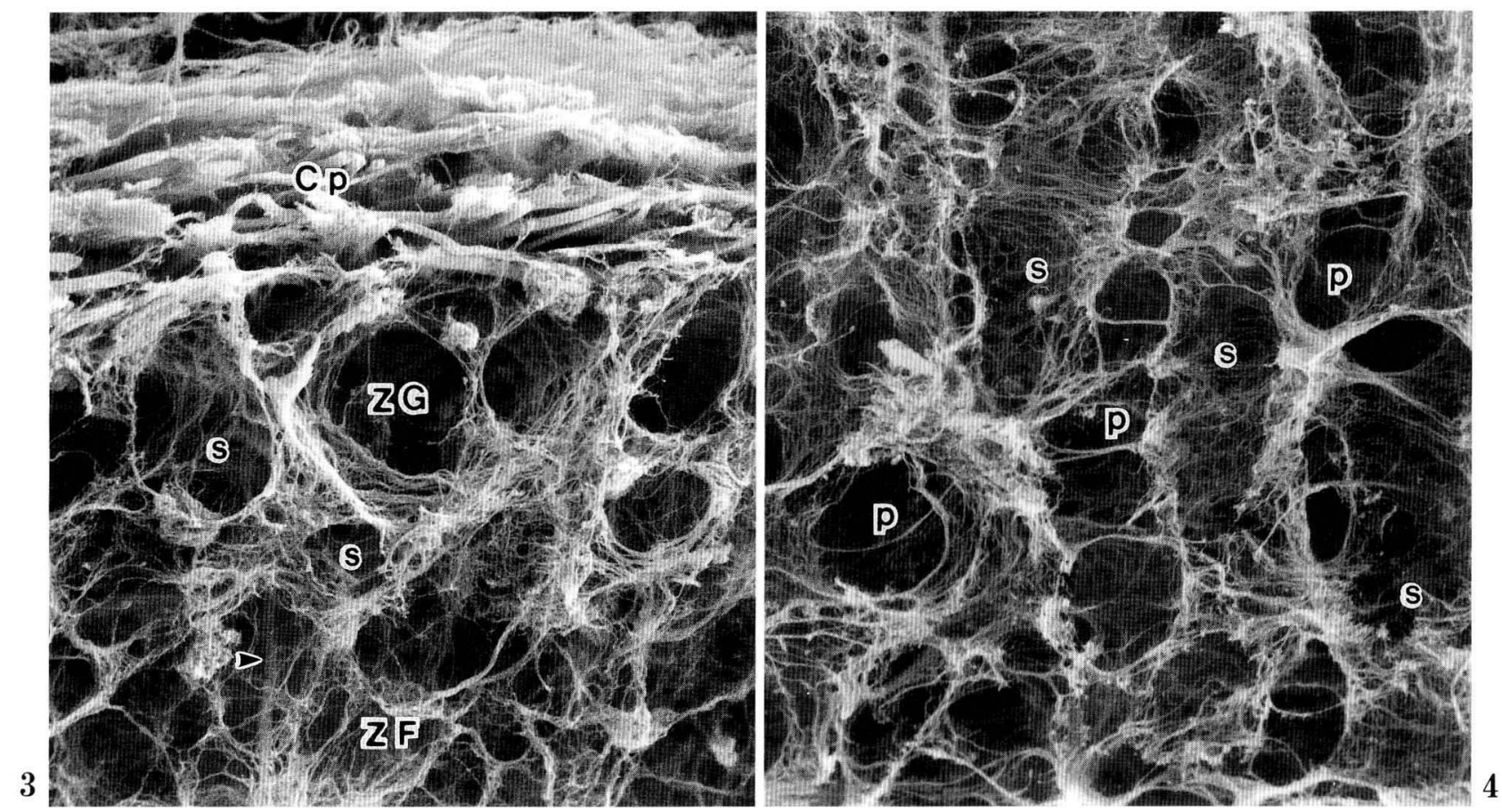

- Fig. 3. SEM micrograph showing a cut surface of the collagen networks of the capsule $(C p)$ and zona glomerulosa $(Z G)$ of the rat adrenal gland. The capsular network is composed of a layered plexus of thick bundles of collagen fibrils. Round spaces for the cortical parenchymal cells of the zona glomerulosa are formed by collagen fibrillar sheaths. A bundle of collagen fibrils (arrowhead) runs straight down into the zona fasciculata $(Z F)$. $s$ Spaces for housing cortical capillaries. $\times 1,000$

Fig. 4. SEM view of the radially sectioned collagen networks of the zona fasciculata. Collagen fibrils underlying cortical capillary endothelial cells form tube-like perivascular sheaths (s). Many bundles of collagen fibrils arising perpendicularly from the perivascular sheaths traverse the intervascular spaces for housing cortical parenchymal cells $(p) . \times 1,000$

Within the meshes of this plexus of tubes extended a fibril plexus of an irregular honey comb-like configuration. The sizes of the individual basket spaces corresponded to those of the cortical cells of the zona reticularis.

At the cortico-medullary junction, collagen fibrils tended to accumulate abundantly and, in some areas, form a definite demarcating fibril layer (Fig. 7). Even in the portions where the fibril layer developed weakly, it was easy to distinguish the boundary between the cortex and medulla, since the arrangement of the collagen fibrils was characteristic of each structure.

The collagen framework of the adrenal medulla presented a characteristic meshwork-pattern of fibrils, reflecting its histological configuration (Figs. 1, 8). Cross sections of the collagen framework of the adrenal medulla showed two major structures, one being a small round basket-like sheath and the other was a tube-like sheath. Collagen fibrils were inter- woven into more tightly meshed sheaths around the peripheral radicles and venous tributaries of the central veins. Collagen fibril sheaths comparted the spaces among these tree-like perivascular sheath tubes into round rooms for containing chromaffin cell nodules and nervous elements.

Individual spaces of the collagen baskets for housing chromaffin cells were not completely closed but were opened through a few small round windows (Figs. 1, 8). Thus, basket spaces continued to adjacent spaces through these windows. Only a few basket spaces were completely isolated from adjacent ones by a collagen fibril sheath.

In the walls of collagen baskets, collagen fibrils ran randomly. In some cases, tens of fibrils coursed side by side to form a fasciculus and then sprayed out in various directions, and again intermingled with other fibrils to form a fibril sheath (Figs. 1c, d, 8). Along the edges of the windows of the collagen baskets, many fibrils ran circularly, forming a distinct rim bordering 

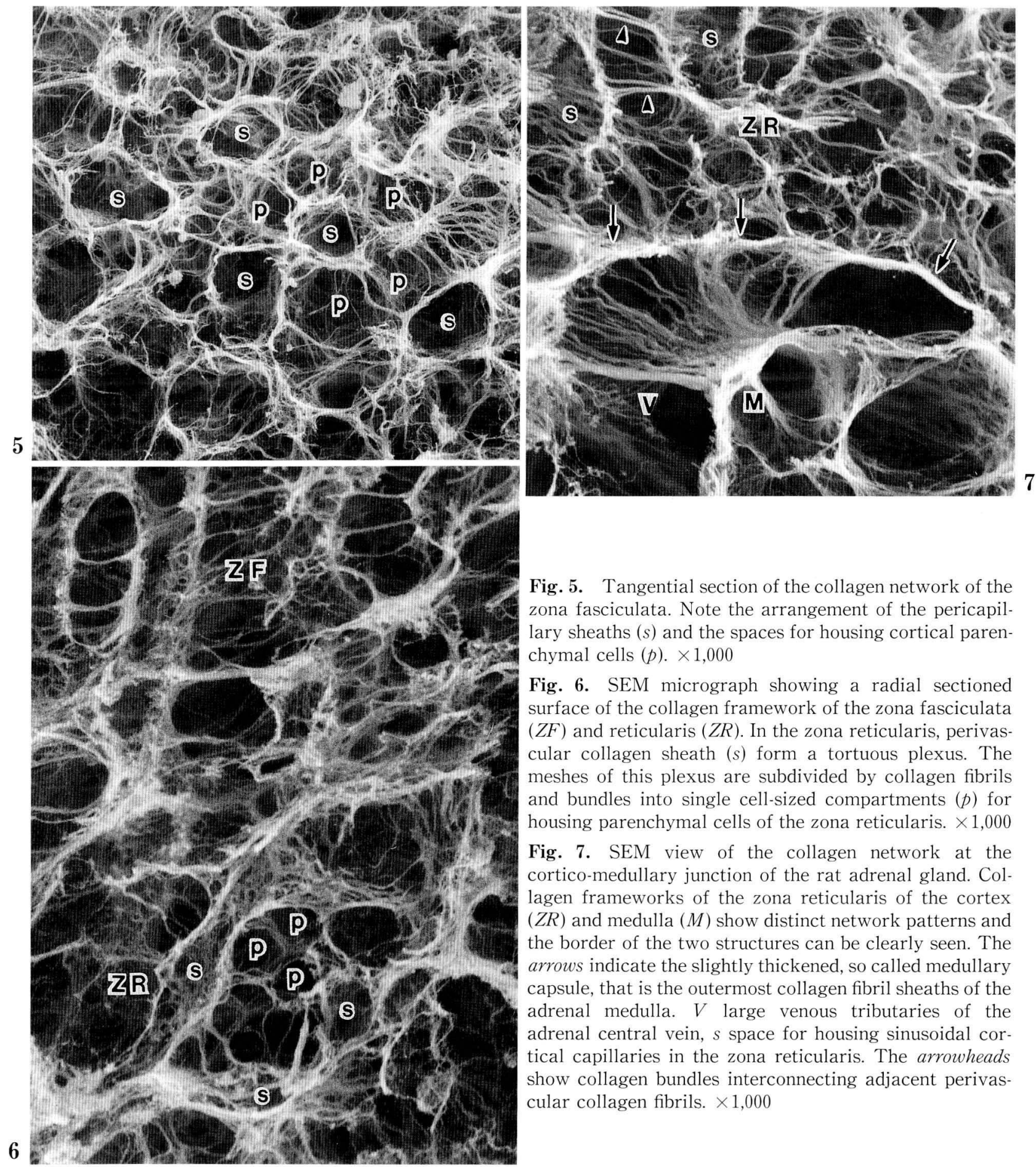

Fig. 5. Tangential section of the collagen network of the zona fasciculata. Note the arrangement of the pericapillary sheaths $(s)$ and the spaces for housing cortical parenchymal cells $(p) . \times 1,000$

Fig. 6. SEM micrograph showing a radial sectioned surface of the collagen framework of the zona fasciculata $(Z F)$ and reticularis $(Z R)$. In the zona reticularis, perivascular collagen sheath $(s)$ form a tortuous plexus. The meshes of this plexus are subdivided by collagen fibrils and bundles into single cell-sized compartments $(p)$ for housing parenchymal cells of the zona reticularis. $\times 1,000$

Fig. 7. SEM view of the collagen network at the cortico-medullary junction of the rat adrenal gland. Collagen frameworks of the zona reticularis of the cortex $(Z R)$ and medulla $(M)$ show distinct network patterns and the border of the two structures can be clearly seen. The arrows indicate the slightly thickened, so called medullary capsule, that is the outermost collagen fibril sheaths of the adrenal medulla. $V$ large venous tributaries of the adrenal central vein, $s$ space for housing sinusoidal cortical capillaries in the zona reticularis. The arrowheads show collagen bundles interconnecting adjacent perivascular collagen fibrils. $\times 1,000$

Fig. 8. SEM view of the collagen framework of the rat and adrenal medulla. a. Collagen fibrils embracing peripheral radicles of the central vein $(V)$ form fine-meshed collagen fibrillar sheath tubes. The spaces extending among the peripheral radicles are subdivided by collagen sheaths into round, basket-like compartments for containing chromaffin cell clusters $(B)$. Note open fenestrae $(F)$ in the wall through which the space is communicated to the adjacent basket-like spaces. Thin tube-like spaces for housing medullary capillaries $(m)$ are localized in the interstices between the basket-like sheaths. $\times 900$. b. A closer view of the wall of the basket-like compartment interpositioned between the chromaffin cells and the peripheral radicles of the central vein. $\times 5,000$. c. Surrounding nervous elements in the medulla, collagen fibrils form a tight fibrillar plexus $(N)$. The arrowheads show tubes for nerve fibers. $\times 1,200$ 

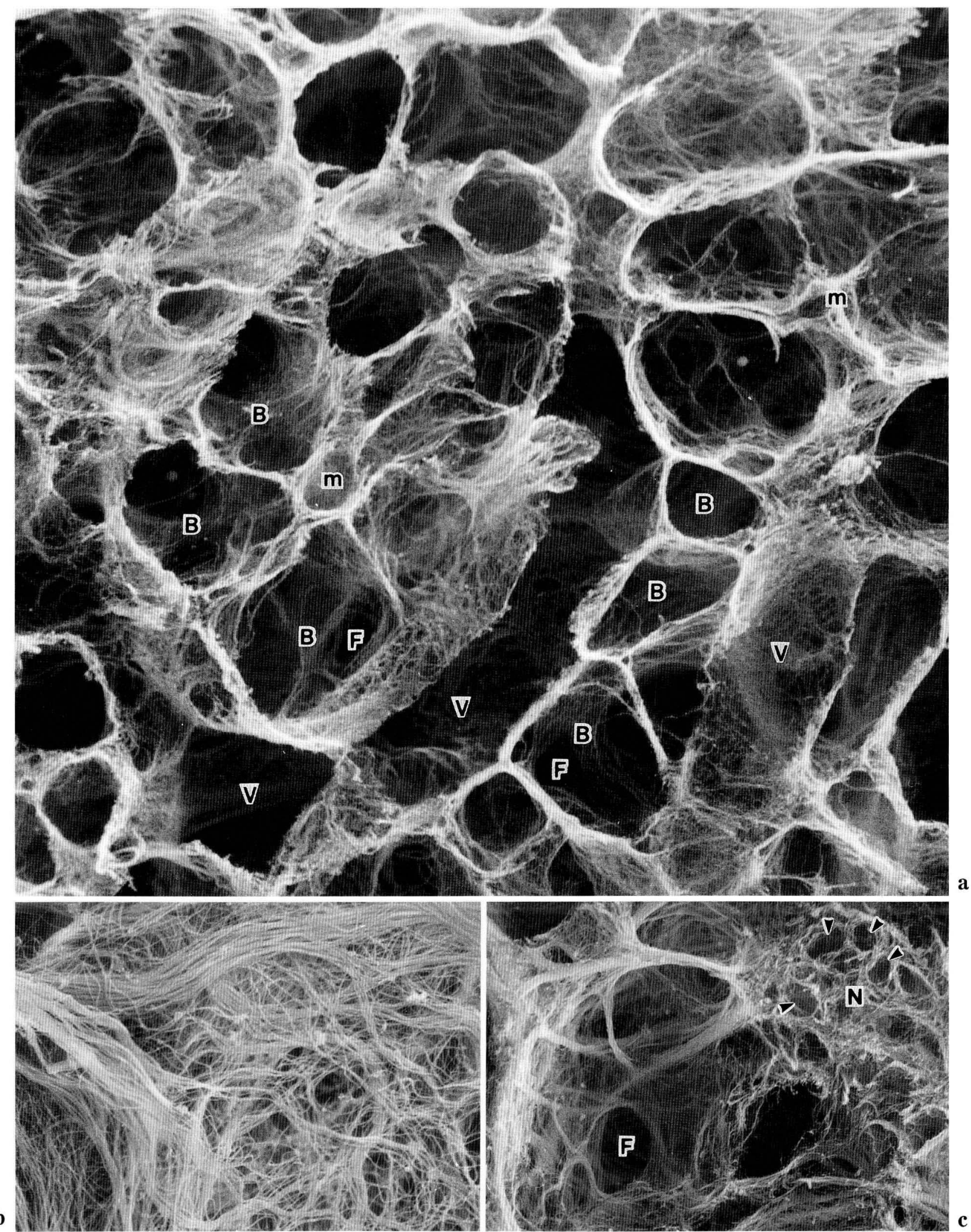

Fig. 8. Legend on the opposite page. 

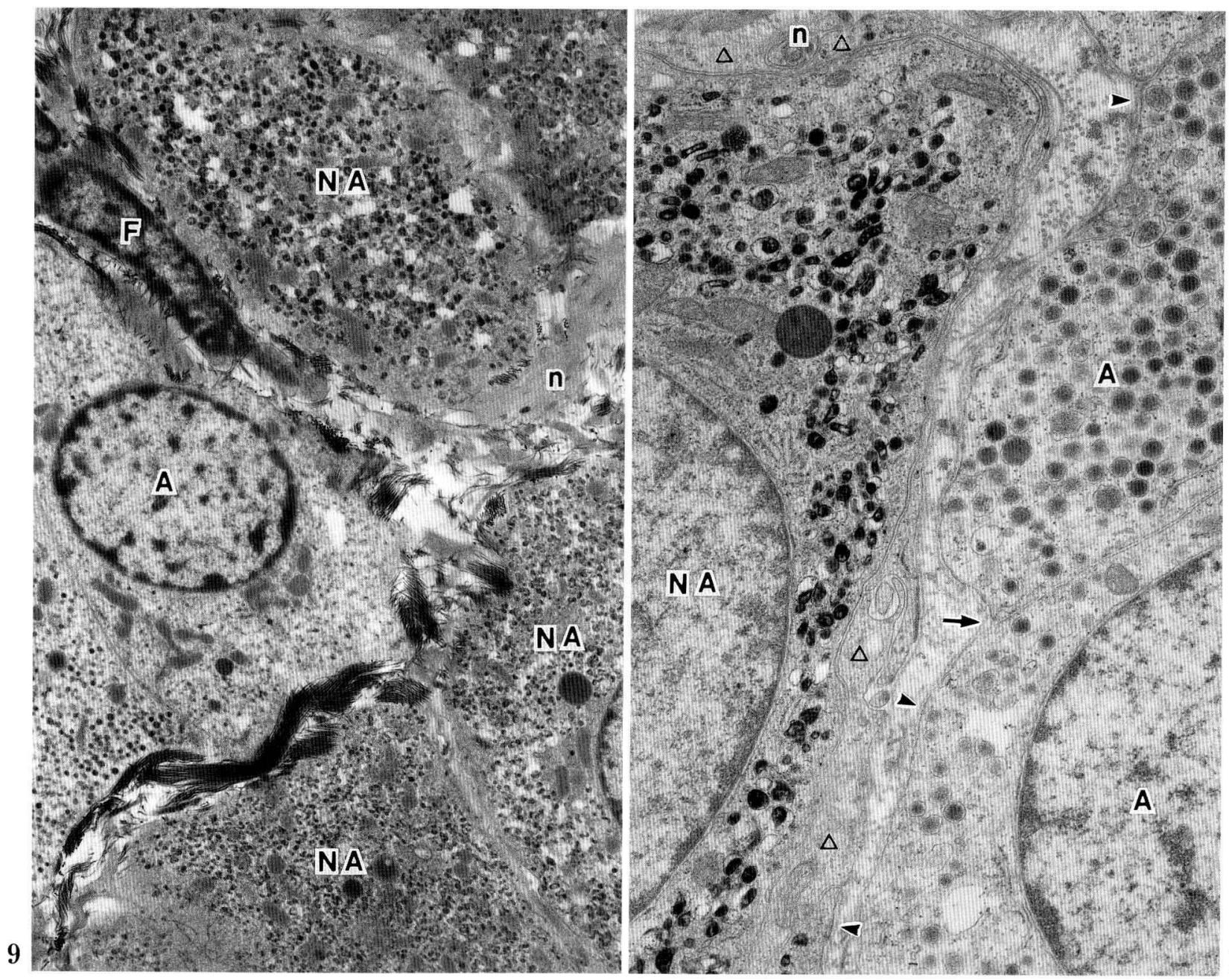

Fig. 9. TEM view of a thick section of tannic acid-treated rat adrenal medulla. Note plentiful collagen fibrils in the connective tissue spaces interpositioned between adrenaline $(A)$ and noradrenaline $(N A)$ cells. $F$ fibroblasts, $n$ nerve fibers. $\times 5,500$

Fig. 10. TEM micrograph of the interface of the adrenaline cells $(A)$ and noradrenaline cells $(N A)$. Collagen fibrils are localized in the connective tissue space, which is between the two basal laminae (arrowheads) of the adrenaline and noradrenaline cell clusters. Note the basal lamina extending between adjacent chromaffin cells bridging over the intercellular space (arrow). $\triangle$ Schwann cell sheath, $n$ nerve fibers. $\times 15,000$

the window. Only a few thin bundles transversed the basket space, apparently corresponding to the fibrils penetrating into the intercellular spaces of chromaffin cells.

In the interstices of the fibrillar baskets of chromaffin cell nodules, tube-like spaces, $10-20 \mu \mathrm{m}$ thick remained (Fig. 8a). These corresponded to the spaces for medullary capillaries. The collagen fibrils of the pericapillary sheaths were intermingled with those of the baskets for chromaffin cell nodules, and showed a conspicuous contrast to those of the peripheral radicular vessels of the central vein.
Most of the basket-like compartments for chromaffin cell nodules were contiguous to the vascular spaces, peripheral radicles of the central vein and/or medullary capillaries. A few rooms were apart from both of the vascular systems. The collagen plexus for housing nerve fibers and associating Schwann cells showed fine meshes of various sizes (Fig. 9c).

Transmission electron micrographs of thick sections $(200-500 \mathrm{~nm})$ of rat adrenal medulla treated with tannic acid indicated clearly the location of collagen fibrils extending among the chromaffin cell clusters (Fig. 9). Adrenaline cells and noradrenaline 
cells tended to be grouped into different clusters. A sheath of basal lamina invested each cell cluster, in which nerve fibers and Schwann cells were enclosed. Schwann cell sheaths frequently enwrapped chromaffin cell clusters (Fig. 10). No collagen fibrils were observed to extend into the intercellular spaces of the chromaffin-cell clusters bounded by the basal lamina.

\section{DISCUSSION}

The present maceration method developed by one of the authors (OHTANI, 1987) enabled us to isolate collagen fibrillar framework of the rat adrenal gland. Classically, FLINT (1900) examined dog adrenal reticulum by MALL's method, in which frozen sections of fresh organs were digested with pancreatin and then washed (MALL, 1896), and described its architecture both in the cortex and medulla. However, in the MALL's method the precise three-dimensional configuration of the fibrous framework was not preserved, since the specimens were not prefixed. Using the present maceration method, we were able to expose the framework of collagen fibrils in a state nearly completely preserving its three-dimensional structure. Scanning electron microscopic observations revealed characteristic meshwork patterns in the adrenal cortex and medulla respectively, and a clear demarcation line could be perceived between the two structures.

Using conventional histological staining methods and silver impregnation, PAULY (1957) described the rat adrenal cortex as a continuum tunneled with cortical capillaries, with individual cortical cells in all three zones invested and supported by a network of reticular fibers. The present observations showed that the collagen framework of the rat adrenal cortex is mainly composed of two kinds of fibril networks, one being a pericapillary sheath of smaller meshworks, and the other a coarse network of collagen bundles, connecting adjacent perivascular capillary sheaths, thus giving the appearance of the rungs of ladders. By transmission and scanning electron microscopy of the adrenal cortex processed with usual fixation methods, collagen fibrils have been shown to be intermingled with numerous microvilli arising from the cortical cells in the pericapillary spaces (MotTA et al., 1979; NozAKI and MiYoshi, 1984). In the space between the cells, which were aligned centripetally, only a few collagen fibrils crossed. Thus, individual cortical cells of the zona fasciculata are considered not to be tightly restricted by collagen fibrils, providing no obstacle for cortical cells to move in a centrpetal direction.

It has been noted that a layer of connective tissue is intercalated between the cortex and medulla in a variety of mammals (BACHMANN, 1954; PAULY, 1957; HOLMES, 1968). Such a layer was called the 'Markkapsel' (BACHMANN, 1954). In the rat, a similar layer was reported to be present but incomplete (PAULY, 1957). In the present study, we could easily define the boundary between the cortex and medulla, since at the corticomedullary junction there was a collagen fibril layer slightly thicker than the fibril sheath seen in the cortex. However, its network pattern and thickness were similar to those of collagen fibril sheaths of the medulla. Thus the 'medullary capsule' of the rat adrenal gland can be considered to be the outermost collagen sheaths of the medullarly collagen framework, and there are no independent, definite, proper medullary capsules in the rat adrenal gland.

The mammalian adrenal medulla is composed of clumps or cords of chromaffin cells. A collagen sheath enwraps these cell cords (BACHMANN, 1954; Coupland, 1984). BENNETT and Kilham (1941) considered that, in the cat adrenal medulla, medullary chromaffin cells are of a polarized columnar epithelial cell type with the nucleus shifted to the cell base closely associated with a blood capillary, while the apical cell region abuts on a vein: thus the medullary cells possess polarity with respect to the blood vessels. In the rat, however, as shown in the present examination, every medullary chromaffin cell strand is enwrapped with a basket-like collagen sheath. Further, it has been reported that, within the chromaffin cell clusters or strands, are located intercellular canaliculi which are free of connective tissue elements and contain microvillous processes of chromaffin cells as well as bare nerve fibers (ELFVIN, 1965; Coupland, 1965, 1984). Thus, it would be more exact to say that, at least in the rat, adrenal chromaffin cells reside on the collagen fibril sheath and possess a polarity, their basal pole being directed toward the collagen sheath and their apical regions toward the inside of the cell nodules.

The connective tissue spaces where the collagen networks extend are extravascular paths connecting perivascular and pericellular spaces; they function as the transport routes for metabolites and hormones (KiHARA, 1950; LIVINGSTON and WilKS, 1976; CASEley-SMith, 1977; MEYer and Silberberg, 1977). In the adrenal medulla, the chromaffin cells, may thus exchange their metabolites and physiological messengers via the adjacent connective tissue spaces. The blood which drains the adrenal cortex flows through the medulla, since most of the cortical capillaries drain into the tree-like vascular system of peripheral 
radicles of the central vein within the medulla (Flint, 1900; BennetT and Kilham, 1940; Gersh and Grollman, 1941; Lever, 1952; Coupland and Selby, 1976; Kikuta and Murakami, 1982, 1984; MURAKAMI et al., 1989). The chromaffin cells are thus considered to be adequately exposed to cortical hormones, regardless of the distance between the venous lumen and individual chromaffin cells.

In the adrenal medulla, a large variety of bioactive peptides besides catecholamines, which are known to function as neurotransmitters or neuromodulators, have been reported to be present in chromaffin cells, nerve fibers and ganglion cells (KONDO, 1985; FUJITA et al., 1988). Biogenic amines, such as adrenaline or noradrenaline, are secreted in a large amount and function as hormones transferred by the systemic blood flow. However, other physiological messengers that are secreted only in small amounts may diffuse first within the narrow intercellular space and then reach the basal lamina of chromaffin cells which invest the whole of the chromaffin cell nodules. Across this basal lamina, the substances may diffuse into the connective tissue spaces. These spaces are much wider than the intercellular spaces of chromaffin cells.

It may thus be inferred that such bioactive sub-

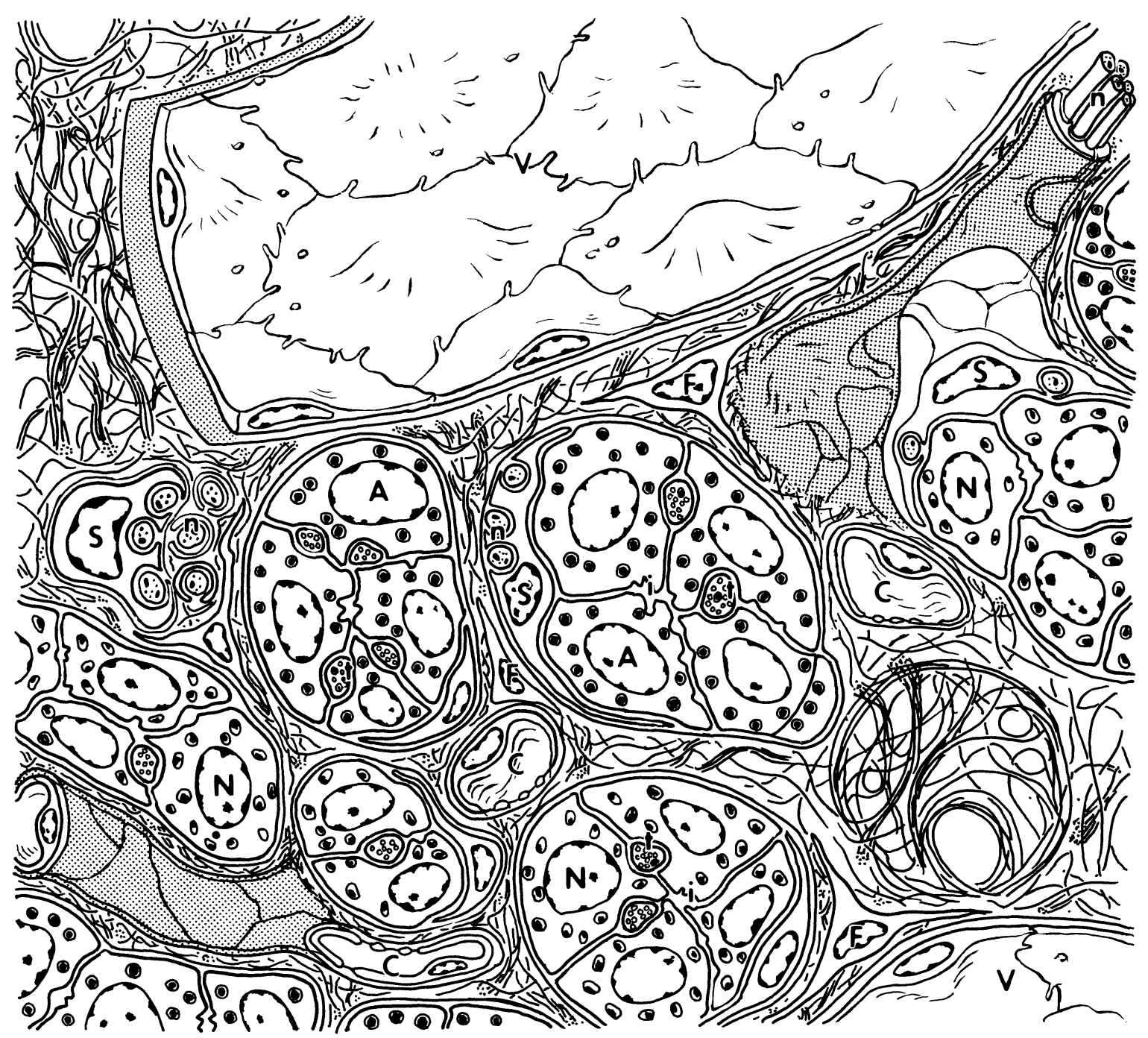

Fig. 11. Diagram showing the compartmentalized organization of the rat adrenal medulla. Dotted areas indicate basal lamina. $A$ adrenaline, $N$ noradrenaline cells, $V$ peripheral radicles of the central vein, $C$ medullary capillaries, $S$ Schwann cells, $F$ fibroblasts, $n$ nerve fibers, $t$ nerve terminals, $i$ intercellular canaliculi. 
stances would be abruptly diluted within the connective tissue spaces and their effects might be lost immediately. The connective tissue spaces in the adrenal medulla thus may work as partition walls between the adjacent cell clusters into which different nerve fibers may terminate. Furthermore, the compartmentalized architecture of the adrenal medulla composed of collagen sheaths suggests the existence of a compartmentalized transport of various bioactive substances within the adrenal medulla. A schematic representation of the architecture of the rat adrenal medulla is shown in Figure 11.

Acknowledgments. The authors are grateful to Mr. Nobuo HAYASHI and Mr. Noboru Kishimoto (Central Research Laboratory of Okayama University Medical School) for their technical help in electron microscopy.

\section{REFERENCES}

Abraham, M., M. Kieselstein and S. Lisson-Begon: The extravascular channel system in the rostral pituitary of Mugil cephalus (Teleostei) as revealed by use of horseradish peroxidase. Cell Tiss. Res. 167: 289-296 (1976).

Bachmann, R.: Die Nebenniere. In: (ed. by) W. V. MÖLlENDORFF and W. BARGMANN: Handbuch der mikroskopischen Anatomie des Menschen, VI/5. Springer-Verlag, Berlin-Göttingen-Heidelberg, 1954 (p. 1-952).

BennetT, H. S. and L. Kilham: The blood vessels of the adrenal gland of the adult cat. Anat. Rec. 77: 447-471 (1940).

Casley-Smith, J. R.: Channels through the interstitial tissue. Bibl. Anat. 15 (Part I): 206-209 (1977).

Coupland, R. E.: Electron microscopic observations on the structure of the rat adrenal medulla. I. The ultrastructure and organization of chromaffin cells in the normal adrenal medulla. J. Anat. 99: 231-254 (1965).

- Ultrastructural features of the mammalian adrenal medulla. In: (ed. by) P. M. MotTA: Ultrastructure of endocrine cells and tissues. Martinus Nijhoff Publishers, Boston-The Hague-Dordrecht-Lancaster, 1984 (p. 168-179).

Coupland, R. E. and J. E. Selby: The blood supply of the mammalian adrenal medulla: A comparative study. J. Anat. 122: 539-551 (1976).

Elfvin, L. G.: The fine structure of the cell surface of chromaffin cells in the rat adrenal medulla. J. Ultrastr. Res. 12: 263-286 (1965).

Fuint, J. M.: The blood-vessels, angiogenesis, organogenesis, reticulum, and histology of the adrenal. Johns Hopkins Hosp. Rep. 9: 153-229 (1900).

FuJiTA, T.: Messenger substances of neurons and paraneurons: Their chemical nature and the routes and ranges of their transport to targets. Biomed. Res. 4:
239-256 (1983).

Fujita, T., T. Kanno and S. Kobayashi: The paraneuron. Springer-Verlag, Tokyo-Berlin-Heidelberg-New York-London, 1988 (p. 72-77).

Gersh, I. and A. Grollman: The vascular pattern of the adrenal gland of the mouse and rat and its physiological response to changes in glandular activity. Contrib. Embryol. Carnegie Inst. 29: 113-125 (1941).

Holmes, R. L.: The adrenal glands of Macaca mulatta, with special reference to the cortico-medullary zone. J. Anat. 103: 471-477 (1968).

KIHARA, J.: Extravasculäre Saftbahnsystem. In: (ed. by) Japanese Association for Hematology: Symposium on hematology (In Japanese). Nagai-Shoten, Tokyo, 1950 (Vol. 3, p. 118-159).

Kikuta, A. and T. Murakami: Microcirculation of the rat adrenal gland: a scanning electron microscope study of vascular casts. Amer. J. Anat. 164: 19-28 (1982).

: Relationship between chromaffin cells and blood vessels in the rat adrenal medulla: A transmission electron microscopic study combined with blood vessel reconstructions. Amer. J. Anat. 170: 73-81 (1984).

Kondo, H.: Immunohistochemical analysis of the localization of neuropeptides in the adrenal gland. Arch. Histol. Jap. 48: 453-481 (1985).

LEVER, J. D.: Observations on the adrenal blood vessels in the rat. J. Anat. 86: 459-467 (1952).

Livingston, A. and P. N. Wilks: Perivascular regions of the rat neural lobe. Cell Tiss. Res. 174: 273-280 (1976).

Mall, F. P.: Reticulated tissue, and its relation to the connective tissue fibrils. Johns Hopkins Hosp. Rep. 1: 171-208 (1896).

Meyer, F. A. and A, Silberberg: The extravascular space: Function of the main structural elements. Bibl. Anat. 15 (Part I): 213-219 (1977).

MotTa, P., M. Muto, and T. Fujita: Three dimensional organization of mammalian adrenal cortex: A scanning electron microscopic study. Cell Tiss. Res. 196: 23-38 (1979).

Murakami, T.: A revised tannin-osmium method for non-coated scanning electron microscope specimens. Arch. Histol. Jap. 39: 99-103 (1974).

Murakami, T., H. Oukouchi, Y. Uno, A. Ohtsuka and T. TAguchi: Blood vascular beds of rat adrenal and accessory adrenal glands, with special reference to the corticomedullary portal system: A further scanning electron microscopic study of corrosion casts and tissue specimens. Arch. Histol. Cytol. 52: 461-476 (1989).

Nozaki, F. and M. Miyoshi: Perisinusoidal cells in a three-dimensional organization of the adrenal cortex in the monkey. Arch. Histol. Jap. 47: 345-357 (1984).

Ohtani, 0.: Three-dimensional organization of the connective tissue fibers of the human pancreas: A scanning electron microscopic study of $\mathrm{NaOH}$ treated-tissues. Arch. Histol. Jap. 50: 557-566 (1987).

-: Three-dimensional organization of the collagen fibrillar framework of the human and rat livers. Arch. Histol. Cytol. 51: 473-488 (1988). 
Ohtani, O., T. Ushiki, T. Taguchi and A. Kikuta: Collagen fibrillar networks as skeletal frameworks: A demonstration by cell-maceration/scanning electron microscope method. Arch. Histol. Cytol. 51: 249-261 (1988).

Pauly, J. E.: Morphological observations on the adrenal cortex of the laboratory rat. Endocrinology 60: 247-264 (1957).
Dr. Akio Kikuta

Department of Anatomy

Okayama University Medical School 2-5-1 Shikata-cho, Okayama 700 Japan

菊田彰夫

700 岡山市鹿田町 2-5-1

岡山大学医学部

第二解剖学教室 